\title{
Lentigo Maligna - Not Always a Face and Neck Disease of the Elderly
}

\author{
Ana Filipa Duarte ${ }^{a, b}$ Bernardo Sousa-Pinto ${ }^{b-d}$ Ana Margarida Barros ${ }^{a}$ \\ Eckart Haneke $^{\mathrm{a}, \mathrm{e}-\mathrm{g}}$ Osvaldo Correia ${ }^{\mathrm{a}, \mathrm{c}, \mathrm{d}}$

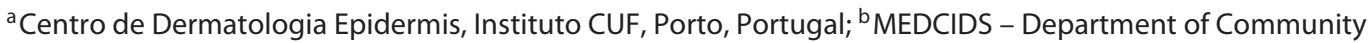 \\ Medicine, Information and Health Decision Sciences, Faculty of Medicine, University of Porto, Porto, Portugal; \\ 'CINTESIS - Center for Health Technology and Services Research, University of Porto, Porto, Portugal; ${ }^{\mathrm{d} B a s i c}$ and \\ Clinical Immunology Unit, Department of Pathology, Faculty of Medicine, University of Porto, Porto, Portugal; \\ e Department of Dermatology, Inselspital, University of Bern, Bern, Switzerland; ${ }^{f}$ Dermatology Clinic Dermaticum, \\ Freiburg, Germany; ${ }^{9}$ Department of Dermatology, University of Ghent, Ghent, Belgium
}

\section{Keywords}

Lentigo maligna · Extrafacial location · Early diagnosis

\begin{abstract}
Introduction: Lentigo maligna (LM) is a rare form of in situ melanoma, frequently seen as a large patch in elderly patients. The aim of this study was to assess clinical and dermoscopic features of LM. Material and Methods: A retrospective study of LM patients presenting to our center between July 2007 and July 2017 was performed. Demographic data, anatomical location, laterality, diameter, Clark level, Breslow stage, "ABCD" signs and dermoscopic features were registered. Facial versus extrafacial LM were compared. Results: We found $21 \mathrm{LM}$, of which 12 had an extrafacial location and 9 a facial location. Half of the extrafacial lesions were located on an upper limb. The median age at diagnosis was 63 years (ranging from 38 to 84 years). Most LM cases were female $(16 / 21)$ with phototype II (13/21). More than half of the patients $(11 / 21)$ had a history of a skin neoplasm or actinic keratosis. The median diameter found was $6 \mathrm{~mm}$ (interquartile range $=4.5 \mathrm{~mm}$ ), ranging from 1 to $15 \mathrm{~mm}$. Five lesions were invasive (median Breslow depth of $0.2 \mathrm{~mm}$ ), and 4 of them
\end{abstract}

(c) 2018 S. Karger AG, Basel were extrafacial. Discussion: In this study LM was more frequently found in an extrafacial location and as a small patch with a 6-mm diameter medium. The epidemiology of LM/LM melanoma might be changing. Full body examination and dermoscopy are of the utmost importance for the diagnosis. Dermatologists should be aware and search for small lesions outside the face and neck, particularly in middle-aged female patients with photo-damaged skin.

(C) 2018 S. Karger AG, Basel

\section{Introduction}

Lentigo maligna (LM) is relatively rare form of malignant melanoma (MM), corresponding to $4-15 \%$ of all MM cases [1]. LM usually occurs in sun-damaged skin and is typically poorly circumscribed; its diagnosis is based on atypical junctional melanocytic hyperplasia combined with solar elastosis and epidermal atrophy $[1,2]$. When LM invades the dermis, it is called lentigo maligna melanoma (LMM). The exact percentage of LM evolving to LMM is not clear, varying from 5 to $50 \%$ $[1,3]$.

\section{KARGER}

E-Mail karger@karger.com

www.karger.com/drm
Ana Filipa Duarte, MD

Centro de Dermatologia Epidermis, Instituto CUF

Rua Fonte das Sete Bicas, 170, piso 2

PT-4460-188 Sra da Hora, Matosinhos, Porto (Portugal)

E-Mail duarte.af.t30@gmail.com 
LM occurs almost exclusively in middle-aged and elderly Caucasians [2]; its incidence is increasing because of a higher cumulative exposure to ultraviolet radiation [4]. Classically, LM presents as a slowly enlarging patch with variable color and with ill-defined borders, most frequently located on the head and neck (86\%), with predilection for the cheeks [5].

The clinical presentation may be subtle, particularly in early stages, and therefore, delayed diagnosis is common [4]. Because of its potential significant subclinical extension, LM has a higher risk of local recurrence than other types of correctly treated melanoma. Once LM progresses to its vertically invasive form, its prognosis is similar to that of other types of MM. The diagnosis is a challenge in most

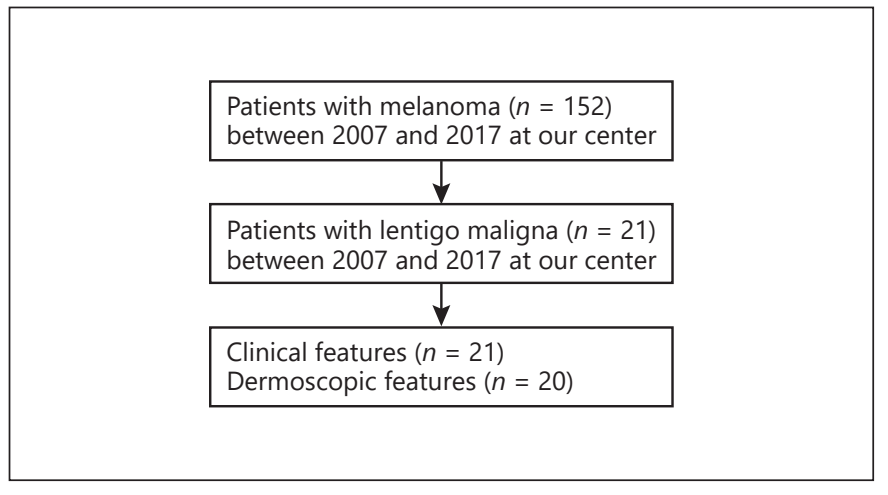

Fig. 1. Flowchart of the Methods.
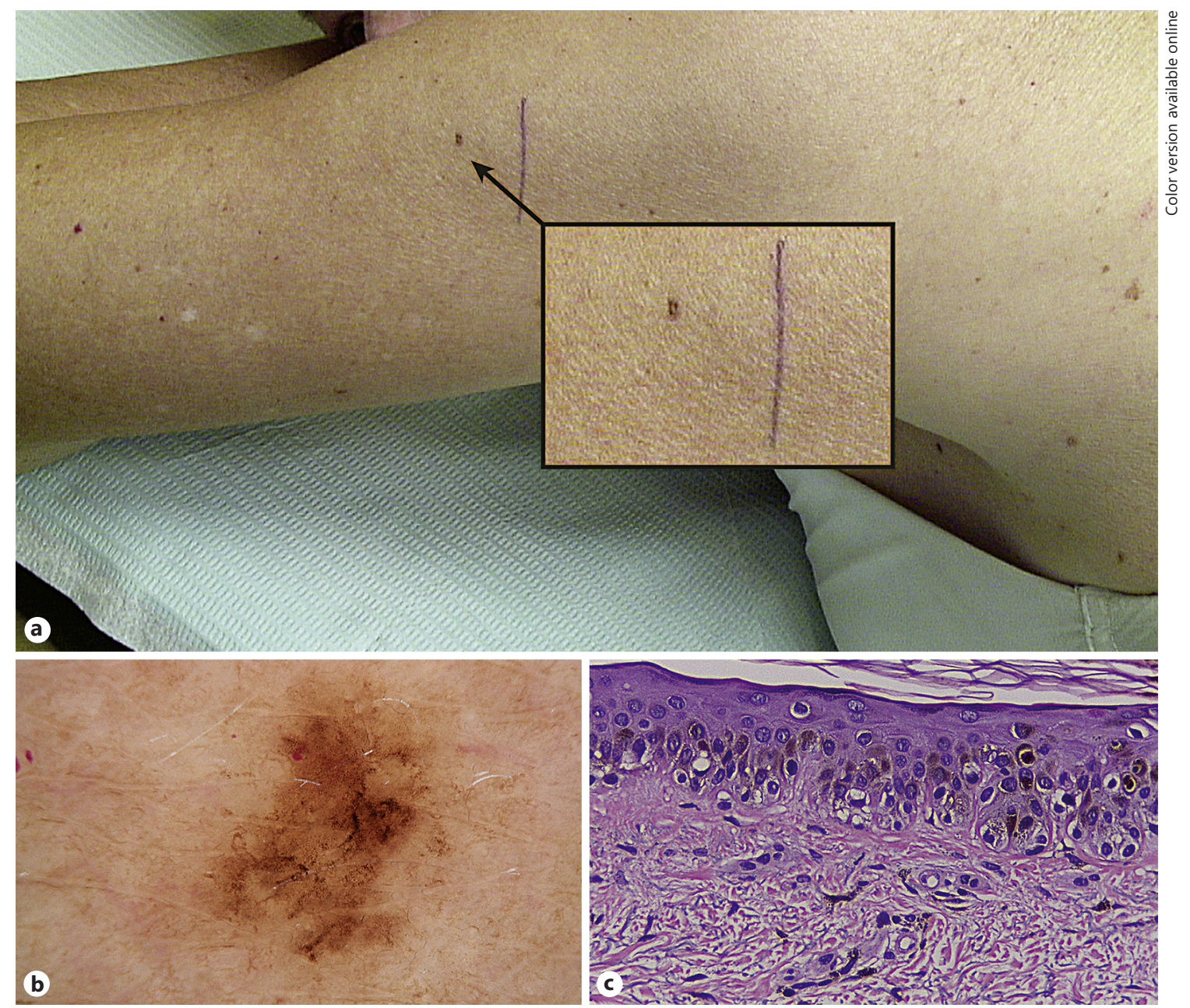

Fig. 2. Lentigo maligna. a Hyperpigmented patch, $3 \mathrm{~mm}$ in diameter, on the left arm, in a photo-damaged area, of a woman in her sixties. b Dermoscopy $(\times 30)$ : atypical pigmented network, irregular striae. c Histopathology $(\times 10)$ : atypical melanocyte proliferation, small nests, pagetoid spread and light halo melanocytes. 
Table 1. Description of cases of facial and extrafacial lentigo maligna (LM) in 21 patients

\begin{tabular}{|c|c|c|c|}
\hline & $\begin{array}{l}\text { Facial LM } \\
(n=9)\end{array}$ & $\begin{array}{l}\text { Extrafacial LM } \\
(n=12)\end{array}$ & $\begin{array}{l}\text { Total } \\
(n=21)\end{array}$ \\
\hline \multicolumn{4}{|l|}{ Gender, $n(\%)$} \\
\hline Male & $1(11.1)$ & $4(33.3)$ & $5(23.8)$ \\
\hline Female & $8(88.9)$ & $8(66.7)$ & $16(76.2)$ \\
\hline Age (median, IQR), years & $63(10)$ & $64(16)$ & $63(15)$ \\
\hline \multicolumn{4}{|l|}{ Working status, $n(\%)$} \\
\hline Active & $6(66.7)$ & $8(66.7)$ & $14(66.7)$ \\
\hline Retired & $3(33.3)$ & $4(33.3)$ & $7(33.3)$ \\
\hline History of living in a tropical country, $n(\%)$ & $2(22.2)$ & $0(0)$ & $2(9.5)$ \\
\hline Immunosuppressive therapy, $n(\%)$ & $0(0)$ & $0(0)$ & $0(0)$ \\
\hline \multicolumn{4}{|l|}{ Phototype, $n(\%)$} \\
\hline I & $1(11.1)$ & $1(8.3)$ & $2(9.5)$ \\
\hline II & $5(55.6)$ & $8(66.7)$ & $13(61.9)$ \\
\hline III & $3(33.3)$ & $3(25.0)$ & $6(28.6)$ \\
\hline \multicolumn{4}{|l|}{ Number of nevi, $n(\%)$} \\
\hline$<25$ & $6(66.7)$ & $7(58.3)$ & $13(61.9)$ \\
\hline $25-50$ & $1(11.1)$ & $5(41.7)$ & $6(28.6)$ \\
\hline $51-100$ & $2(22.2)$ & $0(0)$ & $2(9.5)$ \\
\hline Guttate hypomelanosis, $n(\%)$ & $8(88.9)$ & $8(66.7)$ & $16(76.2)$ \\
\hline History of other neoplasms/lesions, $n(\%)$ & $5(55.6)$ & $7(58.3)$ & $12(57.1)$ \\
\hline Melanoma & $1(11.1)$ & $0(0)$ & $1(4.8)$ \\
\hline Basal cell carcinoma & $3(33.3)$ & $2(16.7)$ & $5(23.8)$ \\
\hline Squamous cell carcinoma & $2(22.2)$ & $2(16.7)$ & $4(19.0)$ \\
\hline Actinic keratosis & $5(55.6)$ & $6(50.0)$ & $11(52.4)$ \\
\hline Other neoplasms ${ }^{\mathrm{a}}$ & $1(11.1)$ & $1(8.3)$ & $2(9.5)$ \\
\hline Family history of skin neoplasms ${ }^{\mathrm{b}}, n(\%)$ & $1(14.3)$ & $0(0)$ & $1(6.2)$ \\
\hline Melanoma & $0(0)$ & $0(0)$ & $0(0)$ \\
\hline Basal cell carcinoma & $1(14.3)$ & $0(0)$ & $1(6.2)$ \\
\hline Squamous cell carcinoma & $1(14.3)$ & $0(0)$ & $1(6.2)$ \\
\hline Solar lentigo, $n(\%)$ & $8(88.9)$ & $12(100)$ & $20(95.2)$ \\
\hline \multicolumn{4}{|l|}{ Laterality, $n(\%)$} \\
\hline Left & $5(55.6)$ & $5(41.7)$ & $10(47.6)$ \\
\hline Right & $2(22.2)$ & $7(58.3)$ & $9(42.9)$ \\
\hline Nonapplicable & $2(22.2)$ & $0(0)$ & $2(9.5)$ \\
\hline Diameter (median, IQR), mm & $5.6(3.2)$ & $5.0(3.3)$ & $6.0(4.5)$ \\
\hline Diameter $>12 \mathrm{~mm}$ & $3(33.3)$ & $0(0)$ & $3(14.3)$ \\
\hline Invasive $\mathrm{LM}^{\mathrm{c}}, n(\%)$ & $1(11.1)$ & $4(33.3)$ & $5(23.8)$ \\
\hline Breslow depth ${ }^{\mathrm{c}}$ (median, IQR), mm & $0.4(0)$ & $0.2(0.1)$ & $0.2(0.1)$ \\
\hline Amelanotic LM, $n(\%)$ & $2(22.2)$ & $1(8.3)$ & $3(14.3)$ \\
\hline “ABCDE” signs, $n(\%)$ & $9(100)^{d}$ & $11(81.7)^{\mathrm{d}}$ & $20(95.2)^{d}$ \\
\hline Asymmetry & $5(55.6)$ & $7(58.3)$ & $12(57.1)$ \\
\hline Border & $6(66.7)$ & $8(66.7)$ & $14(66.7)$ \\
\hline Color & $1(11.1)$ & $5(41.7)$ & $6(28.6)$ \\
\hline Diameter $\geq 6 \mathrm{~mm}$ & $6(66.7)$ & $5(41.7)$ & $11(52.4)$ \\
\hline \multicolumn{4}{|l|}{ Evolution } \\
\hline Evolving lesion & $3(33.3)$ & $3(25.0)$ & $6(28.6)$ \\
\hline De novo lesion & $0(0)$ & $3(25.0)$ & $3(14.3)$ \\
\hline Stable lesion & $0(0)$ & $0(0)$ & $0(0)$ \\
\hline Unknown by the patient & $6(66.7)$ & $6(50.0)$ & $12(57.1)$ \\
\hline
\end{tabular}


Table 1 (continued)

$\begin{array}{lll}\begin{array}{l}\text { Facial LM } \\ (n=9)\end{array} & \begin{array}{l}\text { Extrafacial LM } \\ (n=12)\end{array} & \begin{array}{l}\text { Total } \\ (n=21)\end{array}\end{array}$

Dermoscopic findings ${ }^{\mathrm{e}}, n(\%)$

Atypical pigment network

Disappearance of follicular structures

$1(11.1)$

White striae

Irregular pseudopods

Annular-granular pattern

$7(77.8)$

$1(11.1)$

$0(0)$

Rhomboidal structures

$6(66.7)$

$3(33.3)$

Milky red areas

$2(22.2)$

Multicomponent, $\geq 3$ structures

$6(66.7)$

Peppering

$2(22.2)$

Irregular follicular pigmentation

$6(66.7)$

Irregular dots/globules

$0(0)$

Gray pseudonetwork

$2(22.2)$

Angulated lines

$1(11.1)$

Polymorph vessels, $\geq 2$ types

$2(22.2)$

Dot vessels

$1(11.1)$

Hook vessels

$0(0)$

Glomerular vessels

Irregular linear vessels

$0(0)$

$2(22.2)$

Helicoidal vessels

$2(22.2)$

$10(90.9)$
$0(0)$
$0(0)$
$3(27.3)$
$0(0)$
$0(0)$
$2(18.2)$
$1(9.1)$
$3(27.3)$
$0(0)$
$2(18.2)$
$0(0)$
$0(0)$
$0(0)$
$1(9.1)$
$0(0)$
$1(9.1)$
$1(9.1)$
$0(0)$

$11(55.0)$

7 (35.0)

$1(5.0)$

$3(15.0)$

$6(30.0)$

$3(15.0)$

$4(20.0)$

7 (35.0)

$5(25.0)$

$6(30.0)$

$2(10.0)$

$2(10.0)$

$1(5.0)$

$2(10.0)$

$2(10.0)$

$0(0)$

$1(5.0)$

$3(15.0)$

$2(10.0)$

IQR, interquartile range. ${ }^{\text {a }}$ Includes 1 patient with a history of thyroid cancer and another with a history of leiomyoma. ${ }^{b}$ Family history of melanoma is unknown for 6 patients, while family history of basal cell carcinoma and squamous cell carcinoma is unknown for 5 patients. ${ }^{c}$ All invasive LM were staged as Clark level II and Breslow stage I. ${ }^{\mathrm{d}}$ Frequency of patients presenting with at least 1 "ABCDE" sign. For facial LM, 1/3 of patients only presented with 1 "ABCDE" sign, while $2 / 3$ of them presented with 2 or more criteria. For extrafacial LM, $17 \%$ of patients only presented with 1 sign, while $75 \%$ presented with 2 or more signs. ${ }^{\mathrm{e}}$ Dermoscopic information not available for 1 patient.

cases. Suspicious lesions should undergo dermoscopic evaluation that may contribute to an early diagnosis [6].

The aim of this study was to characterize the clinical and dermoscopic features of LM/LMM in our center during the last decade.

\section{Methods}

For further details, see the online supplementary material (see www.karger.com/doi/10.1159/000489397 for all online suppl. material) (Fig. 1).

\section{Results}

Over the assessed 10-year period, we observed a total of $21 \mathrm{LM}$ (out of 152 melanomas observed within the same period), of which 12 had an extrafacial location. Half of the latter were located on the upper limbs (upper arm: $n=3$; forearm: $n=2$; hand: $n=1$; Fig. 2 ), followed by the lower limbs (lower leg: $n=4$; thigh: $n=1$ ) and the upper back $(n=1)$. In all patients, LM was first suspected by a dermatologist. The median age at diagnosis was 63 years (ranging from 38 to 84 years).

Most LM cases were female (16/21) and occurred in patients with phototype II (13/21) and less than 25 nevi $(13 / 21)$ (Table 1). More than half of the patients (11/21) had a history of a skin neoplasm or actinic keratosis. The median diameter for the assessed LM was $6 \mathrm{~mm}$ (interquartile range, $\mathrm{IQR}=4.5 \mathrm{~mm}$ - ranging from 1 to $15 \mathrm{~mm}$ ), corresponding to a median diameter of $5.1 \mathrm{~mm}$ among females (IQR $=5.3 \mathrm{~mm}$ ) and $8.0 \mathrm{~mm}$ among males $(\mathrm{IQR}=2.5 \mathrm{~mm})$.

Of the "ABCD" signs, asymmetry, irregular border and diameter $\geq 5 \mathrm{~mm}$ were observed in more than half of the neoplasms; however, the presence of at least $3 \mathrm{ABCD}$ signs was only present in 2 out of 6 cases of LM with diameter $<5 \mathrm{~mm}$ (Table 2). The most common dermoscop- 
Table 2. Comparison of the frequency of "ABCDE" signs and dermoscopic findings in lentigo maligna (LM) cases with $<5$ and $\geq 5 \mathrm{~mm}$ diameter

\begin{tabular}{|c|c|c|c|}
\hline & $\begin{array}{l}\text { LM with diameter } \\
<5 \mathrm{~mm}(n=6)\end{array}$ & $\begin{array}{l}\text { LM with diameter } \\
\geq 5 \mathrm{~mm}(n=12)\end{array}$ & $\begin{array}{l}\text { Total } \\
(n=21)\end{array}$ \\
\hline “ABCDE” signs, $n(\%)$ & $2(33.3)^{\mathrm{a}}$ & $10(66.7)^{\mathrm{a}}$ & $12(57.1)^{\mathrm{a}}$ \\
\hline Asymmetry & $2(33.3)$ & $10(66.7)$ & $12(57.1)$ \\
\hline Border & $3(50.0)$ & $11(73.3)$ & $14(66.7)$ \\
\hline Color & $2(33.3)$ & $4(26.7)$ & $6(28.6)$ \\
\hline Diameter $\geq 6 \mathrm{~mm}$ & $0(0)$ & $11(73.3)$ & $11(52.4)$ \\
\hline Evolution $^{\mathrm{b}}$ & $4(66.7)$ & $5(33.3)$ & $9(42.9)$ \\
\hline \multicolumn{4}{|l|}{ Dermoscopic findings ${ }^{\mathrm{c}}, n(\%)$} \\
\hline Atypical pigment network & $5(83.3)$ & $6(42.9)$ & $11(55.0)$ \\
\hline Disappearance of follicular structures & $1(16.7)$ & $6(42.9)$ & $7(35.0)$ \\
\hline White striae & $0(0)$ & $1(7.1)$ & $1(5.0)$ \\
\hline Irregular pseudopods & $1(16.7)$ & $2(14.3)$ & $3(15.0)$ \\
\hline Annular-granular pattern & $1(16.7)$ & $5(35.7)$ & $6(30.0)$ \\
\hline Rhomboidal structures & $0(0)$ & $3(21.4)$ & $3(15.0)$ \\
\hline Milky red areas & $1(16.7)$ & $3(21.4)$ & $4(20.0)$ \\
\hline Multicomponent, $\geq 3$ structures & $1(16.7)$ & $6(42.9)$ & $7(35.0)$ \\
\hline Peppering & $2(33.3)$ & $3(21.4)$ & $5(25.0)$ \\
\hline Irregular follicular pigmentation & $1(16.7)$ & $5(35.7)$ & $6(30.0)$ \\
\hline Irregular dots/globules & $1(16.7)$ & $1(7.1)$ & $2(10.0)$ \\
\hline Gray pseudonetwork & $0(0)$ & $2(14.3)$ & $2(10.0)$ \\
\hline Angulated lines & $0(0)$ & $1(7.1)$ & $1(5.0)$ \\
\hline Polymorph vessels, $\geq 2$ types & $0(0)$ & $2(14.3)$ & $2(10.0)$ \\
\hline Dot vessels & $1(16.7)$ & $1(7.1)$ & $2(10.0)$ \\
\hline Hook vessels & $0(0)$ & $0(0)$ & $0(0)$ \\
\hline Glomerular vessels & $0(0)$ & $1(7.1)$ & $1(5.0)$ \\
\hline Irregular linear vessels & $0(0)$ & $3(21.4)$ & $3(15.0)$ \\
\hline Helicoidal vessels & $0(0)$ & $2(14.3)$ & $2(10.0)$ \\
\hline
\end{tabular}

${ }^{a} \geq 3$ of the ABCD signs. ${ }^{b}$ Evolving or de novo lesion. ${ }^{c}$ Dermoscopic information not available for 1 patient.

ic findings were atypical pigment network (11/20), disappearance of follicular structures (7/20) and multicomponent pattern $(7 / 20)$ (Table 1). Five lesions were invasive - LMM - all of them staged as Clark level II, having a median Breslow depth of $0.2 \mathrm{~mm}(\mathrm{IQR}=0.1 \mathrm{~mm}$ ).

Facial LM were observed for half of the female patients (8/16) but for only one fifth (1/5) of male patients. Results of the comparisons between facial versus extrafacial LM, and between neoplasms of $<5$ versus $\geq 5 \mathrm{~mm}$ diameter are presented in Table 1 and Table 2, respectively.

\section{Discussion}

Despite being a small retrospective series of a single center, this study has some interesting results, particularly regarding the location and median diameter of the assessed neoplasm, as well as the patients' median age.
In fact, in our study, almost $60 \%$ of LM were located outside the face and neck. Extrafacial location had been reported by previous studies, but never to such an extent. In most studies, LM involving the head and neck accounted for $75-85 \%$, and only $15-25 \%$ were outside the face and neck. Patient age and gender distribution were also surprisingly different from those usually described in the literature $[5,7]$ in this study, the median age was lower than usually reported (63 vs. 70-75 years) [7]. In addition, more than three quarters of our patients were female, while most previous studies had reported LM to be more common among males [5, 7].

Changing patterns of sun exposure may contribute to the changing epidemiology of LM. The face is consistently more exposed than other areas, but the relationship between sun exposure and LM/LMM might be complex. The regular use of sunscreens on the face may not totally explain the higher incidence of extrafacial lesions, be- 
cause females typically use more sunscreen all over the year than males (among whom we only found 1 facial lesion).

The median diameter at diagnosis was very small (median of $6 \mathrm{~mm}$; 9 lesions with $\leq 5 \mathrm{~mm}$ ). The bigger lesion observed had $15 \mathrm{~mm}$ and was smaller than the mean diameter found in a Spanish study $(15.8 \mathrm{~mm})$ [7]. Females had a smaller median diameter than males, suggesting a more delayed diagnosis among the latter.

Although the "ABCD" criteria have a good semiological value in the differential diagnosis of pigmented lesions [8], in this study only 2 cases of LM $<5 \mathrm{~mm}$ had 3 signs of this rule, which does therefore not seem to be useful for the diagnosis of early small lesions.

Dermoscopy of facial pigmented lesions has been widely studied $[4,9,10]$. In our series, the most frequent feature for facial LM (particularly in lesions $\geq 5 \mathrm{~mm}$ ) were disappearance of follicular structures, annular granular pattern and irregular follicular pigmentation, but also multicomponent pattern. Dermoscopic features of extrafacial LM include a combination of features of facial LM and in situ superficial spreading MM [9]. None of the extrafacial cases of this series had a single feature of facial LM. Curiously, only 1 case of angulated lines was found; it concerned a facial LM, and not an extrafacial lesion, where this pattern has been previously reported [11].

Reflectance confocal microscopy has been described as an important complementary tool for diagnosis, treat- ment guidance and follow-up of LM $[12,13]$, but it is a time-consuming and highly costly technique. Although more sensitive, it is less specific for the diagnosis of LM [14].

A routine full-body examination of the patients, and a regular photographic documentation with dermoscopy [15], associated with higher suspicions on patients with photo damage or a skin cancer history, may justify the small diameter of the lesions in this study. Clinical suspicion supported by complete history and close inspection assisted by dermoscopy are of most importance to recognize early LM.

\section{Key Message}

$60 \%$ of lentigo maligna are located in photo-exposed areas outside the head and neck.

\section{Statement of Ethics}

Subjects have given their informed consent for the study.

\section{Disclosure Statement}

The authors have no conflict of interest to declare.

\section{References}

1 McKenna JK, et al: Lentigo maligna/lentigo maligna melanoma: current state of diagnosis and treatment. Dermatol Surg 2006;32:493504.

-2 Smalberger GJ, Siegel DM, Khachemoune A: Lentigo maligna. Dermatol Ther 2008;21: 439-446.

-3 Weinstock MA, Sober AJ: The risk of progression of lentigo maligna to lentigo maligna melanoma. Br J Dermatol 1987;116:303-310.

4 Pralong P, et al: Dermoscopy of lentigo maligna melanoma: report of 125 cases. Br J Dermatol 2012;167:280-287.

5 Cox NH, Aitchison TC, MacKie RM: Extrafacial lentigo maligna melanoma: analysis of 71 cases and comparison with lentigo maligna melanoma of the head and neck. Br J Dermatol 1998;139:439-443.
6 Schiffner R, et al: Improvement of early recognition of lentigo maligna using dermatoscopy. J Am Acad Dermatol 2000;42:25-32.

7 Martinez-Leborans L, et al: Extrafacial lentigo maligna: a report on 14 cases and a review of the literature. Actas Dermosifiliogr 2016; 107:e57-e63.

8 Thomas L, et al: Semiological value of ABCDE criteria in the diagnosis of cutaneous pigmented tumors. Dermatology 1998;197:1117.

9 Lau YN, Affleck AG, Fleming CJ: Dermatoscopic features of extrafacial lentigo maligna. Clin Exp Dermatol 2013;38:612-616.

10 Stolz W, Schiffner R, Burgdorf WH: Dermatoscopy for facial pigmented skin lesions. Clin Dermatol 2002;20:276-278.

-11 Vanden Daelen A, et al: A digital dermoscopy follow-up illustration and a histopathologic correlation for angulated lines in extrafacial lentigo maligna. JAMA Dermatol 2016;152: 200-203.
2 Guitera P, et al: Improving management and patient care in lentigo maligna by mapping with in vivo confocal microscopy. JAMA Dermatol 2013;149:692-698.

13 Gomez-Martin I, et al: Histopathologic and immunohistochemical correlates of confocal descriptors in pigmented facial macules on photodamaged skin. JAMA Dermatol 2017; 153:771-780.

14 Cinotti E, et al: Dermoscopy vs reflectance confocal microscopy for the diagnosis of lentigo maligna. J Eur Acad Dermatol Venereol 2018;17:14791.

15 Nufer KL, Raphael AP, Soyer HP: Dermoscopy and overdiagnosis of melanoma in situ. JAMA Dermatol 2018;154:398-399.

Duarte/Sousa-Pinto/Barros/Haneke/ Correia 